\title{
Неогабін
}

Прегабалін

Позбався болю, ПОРИНЬ У ЖИТтЯ

- Доведена ефективність при нейропатичному болю, фіброміалгії та генералізованому тривожному розладі ${ }^{1-6}$

- Доведена біоеквівалентність оригінальному прегабаліну

- Один з найдоступніших за ціною прегабалінів в Україні ${ }^{8}$

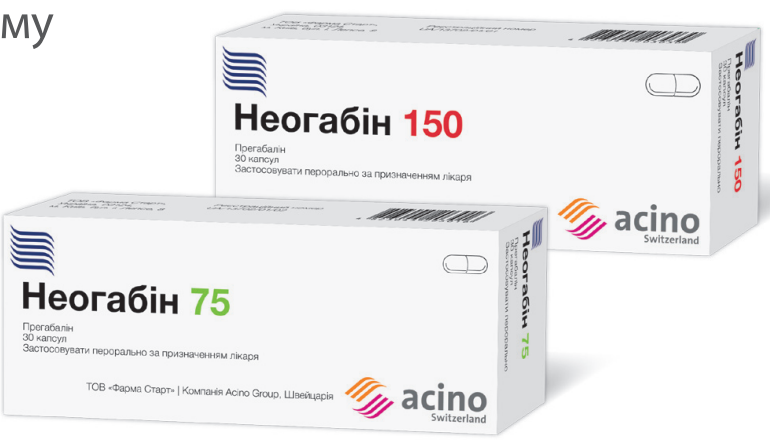

Скорочена інструкція для медичного застосування препарату НЕОГАБІН 75, 150

Діюча речовина. Прегабалін. Лікарська форма. Капсули по 75 мг або по 150 мг. Фармакотерапевтична група. Протиепілептичні засоби. Фармакологічні властивості. Прегабалін зв'язується 3 допоміжною субодиницею (альфа2-дельта-білок) потенціалозалежних кальцієвих каналів у центральній нервовій системі. Показання. Невропатичний біль. Епілепсія. Генералізований тривожний розлад. Фіброміалгія. Протипоказання. Піперчутливість до діючоі речовини або будь-якоі із допоміжних речовин. Побічні реакції. Запаморочення і сонливість, посилення апетиту, сплутаність свідомості, дезорієнтація, дратівливість, ейфоричㄴ. ний настрій, зниження лібідо, безсоння, атаксія, порушення координації, порушення рівноваги, розлади уваги, погіршення пам'яті, тремор, дизартрія, парестезія, седація, в'ялість, головний біль, летаргія, нечіткість зору, диплопія, кон'юнктивіт, вертиго, блювання, запор, сухість у роті, метеоризм, гастроентерит, еректильна дисфункція, імпотенція, периферичний набряк, набряки, порушення ходи, відчуття сп'яніння, втома, збільшення маси тіла тощо. Категорія відпуску. За рецептом. Р. П. МОз України: №UА/13702/01/01, №UA/13702/01/02. Виробник: ТОВ «Фарма Старт», Україна, 03124, м. Київ, бульвар В. Гавела, 8. ТОВ «Фарма Старт» входить до групи компаній Асіно (Швейцарія). Повна інформація знаходиться в інструкціях для медичного застосування препаратів. Інформація для медичних і фармацевтичних працівників, для розміщення в спеціалізованих виданнях $\sum_{i}$ для медичних установ та лікарів, і для розповсюдження на семінарах, конференціях, симпозіумах з медичної тематики.

1. Arezz J.C. et al. BMC Neurology 2008: 8:33. 2. Dworkin R.H. et al. Neurology 2003; 60; 1274-83. 3. Croffrd L.J. et al. Pain 2008; 136(3):419-31. 4. Amold L.M. et al. J Pain. 2008 Sep; 9(9):792-805. 5. Rickels K. et al. Arch Gen Psychiatry. 2005 Sep; 62(9):1022-30. 6. Baldwin D.S. et al. Neuropsychiatr Dis Treat. 2013; 9:883-92. 7. Клінічне дослідження з оцінки біоеквівалентності лікарських препаратів. Код дослідження: PRG-FS. Заключний звіт, 2014,

стор. 8. 8. «Щотижневик АПТЕКА», www.apteka.ua. 


\section{А.И. Осадчий}

Редакция журнала «Український медичний часопис»

\section{Медикаментозная стратегия лечения хронического нейропатического болевого синдрома при радикулопатии}

В обзоре продемонстрирована актуальность проблемы пояснично-крестцовой радикулопатии. Представлены эпидемиологические данные, причины, механизмы развития, клиническая картина и методы фармакотерапии нейропатической боли при радикулопатии. Приведены рекомендации международных организаций по лечению боли. Описана эффективность и безопасность габапентиноидов, в том числе прегабалина как препарата последней генерации, рекомендованного для лечения нейропатической боли. Его клиническая эффективность при нейропатическом болевом синдроме изучена в ряде клинических рандомизированных исследований, продемонстрировавших его анальгезирующее действие, а также способность вызывать регресс сопутствующих психосоматических расстройств и инсомнии у пациентов с пояснично-крестцовой радикулопатией.

Ключевые слова: хроническая боль, боль в спине, нейропатическая боль, ноцицептивная боль, габапентиноиды, прегабалин, радикулопатия.

\section{Актуальность проблемы}

Увеличение продолжительности жизни населения стран с развитой экономикой, накопление в популяции людей преклонного и старческого возраста, гиподинамия - лишь часть причин формирования группы лиц с хроническим болевым синдромом, составной частью которого является нейропатическая боль. Ее формирование обусловлено поражением соматосенсорной системы за счет вовлечения в патологический процесс периферических нервных волокон $\left(\mathrm{A}_{\beta}{ }^{-}, \mathrm{A}_{8}-\right.$ и $\mathrm{C}$-волокна) и центральных нейронов. Нейропатическая боль присутствует у 7-10\% населения в общей популяции (Colloca L. et al., 2017).

Наиболее частой разновидностью нейропатического болевого синдрома (НБС) является хроническая боль в спине, отмечаемая в 20-30\% всех случаев хронического болевого синдрома (Yamashita T. et al., 2014). Патофизиология боли в спине включает комплекс ноцицептивных и нейропатических механизмов, обусловленных повреждением нервных волокон дегенеративными процессами в позвоночнике. Разрушение ноцицептивныхволокон нервного корешка структурами дегенерирующего диска (локальная нейропатическая боль), механической компрессией либо сужением просвета позвоночного канала (механическая нейропатическая корешковая боль) или под воздействием медиаторов воспаления при системных заболеваниях без какой-либо механической компрессии - основная причина развития нейропатической боли при заболевании позвоночника (Freynhagen R., Baron R., 2009).

Проблема приобретает еще большую актуальность в связи с низкой эффективностью лечения, несмотря на обилие современных фармакологических средств. Болезнь имеет хронический, прогрессирующий характер и отрицательно влияет на все сферы жизни пациента, включая сон, настроение, самооценку, работоспособность, межличностные взаимоотношения, и значительно ухудшает качество жизни (Radat F. et al., 2013), требуя существенного повышения расходов на здравоохранение (Berger A. et al., 2004; Knight T. et al., 2013).

В то же время внедрение в лечебную практику препаратов производных габапентиноидов, влияющих на альфа-2-дельтасубъединицы кальциевых каналов, изменяющих ток $\mathrm{Ca}^{2+}$ в нервных волокнах, значительно изменило тактику лечения и повысило клиническую эффективность терапии нейропатической боли. Независимо от первичной причины ее развития препараты этого класса применяют в качестве средств первой линии при купировании НБC (Moulin D.E. et al., 2007).

В настоящем обзоре приведены современные тенденции лечения НБС радикулогенного происхождения, а также проана- лизирована эффективность применения прегабалина - препарата группы габапентиноидов последнего поколения.

Краткий обзор патогенеза формирования НБС

НБС обусловлен поражением соматосенсорной нервной системы вследствие самых разных причин (Attal N. et al., 2008). В таблице приведен их перечень.

Таблица. НБС

\begin{tabular}{ll}
\hline \multicolumn{2}{c}{ Перийропатическая боль } \\
\hline \multicolumn{1}{c}{ Перическая } & \multicolumn{1}{c}{ Центральная } \\
\hline Диабетическая полинейропатия & Постинсультная боль \\
Радикулопатия & Компрессионная \\
(шейного и пояснично-крестцового отделов) & миелопатия при стенозе \\
Алкогольная полинейропатия & спинномозгового канала \\
Острая и хроническая воспалительная полинейропатия Пострадиационная \\
Алиментарно обусловленная полинейропатия & миелопатия \\
Идиопатическая сенсорная нейропатия & Сосудистая миелопатия \\
Компрессия или инфильтрация нерва опухолью & ВиЧ-обусловленная \\
Фантомная боль & миелопатия \\
Постгерпетическая невралгия & Травма спинного мозга (СМ) \\
Тройничного нерва (тригеминальная) невралгия & Боль при рассеянном \\
ВИЧ-обусловленная сенсорная нейропатия & склерозе \\
Туннельная нейропатия & Боль при болезни \\
Боль после мастэктомии & Паркинсона \\
Пострадиационная плексопатия & Сирингомиелия \\
Комплексный регионарный болевой синдром & \\
\hline
\end{tabular}

В патогенезе нейропатической боли различают центральный и периферический компоненты и выделяют следующие механизмы ее развития:

1. Прямая стимуляция чувствительных нейронов при компрессии нервного волокна при дегенеративных заболеваниях позвоночника или его травме.

2. Периферическая ноцицептивная сенситизация медиаторами воспаления и биологически активными веществами, приводящая к снижению порога возбудимости ноцицепторов и повышению уровня их активности, что проявляется в виде гипералгезии или аллодинии.

3. Аномальная эктопическая спонтанная активность поврежденных нервов, лишенных миелинового слоя, способствующая развитию колющей и жгучей боли, а также ощущения парестезии. Ее развитие обусловлено нестабильностью мембранного потенциала за счет перераспределения тетрадоксинрезистентных натриевых каналов поврежденного волокна.

4. Перекрестное возбуждение соседних волокон за счет двунаправленной передачи электрического импульса в зонах электрического контакта волокон различного диаметра, что приводит 
к распространению сигнала во встречных направлениях. Это объясняет извращенное восприятие боли при воздействии неболевых стимулов (аллодиния).

5. Повышение активности адренорецепторов на мембранах аксонов с повышением их чувствительности к катехоламинам и норадреналину, выделяющимся в постганглионарных симпатических волокнах, - механизм, характерный для формирования боли на фоне эмоционального стресса.

6. Прорастание симпатическихволокон в спинномозговой узел, формирование патологического сплетения на телах чувствительных нейронов и спрутинг-процесса при висцеральной соматической боли.

Среди широкого спектра причин, дающих толчок формированию хронического НБС, особое место принадлежит радикулопатии Наиболее часто боль в спине имеет локализацию в поясничнокрестцовом отделе (у 51-80\% пациентов). При этом в большинстве случаев она неспецифична и полиэтиологична по своей природе. В патогенезе ее формирования нейропатический компонент занимает около 60\% (Yamashita T. et al., 2014). Это объясняет феномен различного ощущения боли у пациента: от умеренной до выраженной и изнурительной в зависимости от преобладания одного из механизмов в ее формировании (Yarnitsky D., 2015).

Нейропатический компонент болевого синдрома связан с повреждением нервных структур корешка компрессией костными структурами позвоночника, интерневральным отеком, ишемией или воспалением. При этом происходит повреждение как миелиновой оболочки нервного волокна, так и его самого. Повреждение всех сенсорных периферических волокон (волокон $\mathrm{A}_{\beta}, \mathrm{A}_{\delta}$ и $\mathrm{C}$ с нарушением трансдукции и передачи импульсации из-за нарушений функции ионных каналов (Andre V. et al., 2003) способствует формированию очагов патологического возбуждения (Hurley R.W. et al., 2002). На рис. 1 кратко отображена блок-схема нейропатической болевой депривации.

Патоморфологические особенности формирования нейропатической боли

Поражение соматосенсорной нервной системь
Позитивные симптомы

(симптомы «раздражения»)

Спонтанная боль

Дизестезия

Парестезия

Аллодиния

Гипералгезия
Негативные симптомы (симптомы «выпадения»)
Гипестезия

Анестезия

Гипалгезия

Аналгезия

Рис. 1. Особенности формирования нейропатической боли

Необходимо отметить возможность образования новых патологических синаптических связей (спрутинг-феномен) афферентных аксональных терминалей в заднем роге СМ, что приводит к ошибочному восприятию неболевой информации как болевой за счет перекрестной импульсации между симпатическими и соматосенсорными афферентами и активации симпатических постганглионарных волокон и возбуждению ноцицепторов (Tesfaye S. et al., 2013; Colloca L. et al., 2017). Главным компонентом этого патологического процесса является редукция количества ГАМКсодержащих нейронов в СМ и повышение глутаматергической нейротрансмиссии (Воробьева О., 2014; Finnerup N.B. et al., 2016). Это имеет свое клиническое продолжение, поскольку пациенты проявляют большую изменчивость в ответ на различные фармакологические (с точки зрения типа и дозы) и нефармакологические методы лечения. Ключевым моментом такой изменчивости считают модулирующее влияние коры на восприятие боли. Одна из основных причин хронической боли - появление комплексов гиперреактивных нейронов на различных уровнях центральной нервной системы (ЦНС). Эта активность приводит к функциональным, структурным и адаптивным (нейропластическим) изменениям в головном и СМ, из-за чего болевые ощущения продолжаются даже после устранения производящей причины (Данилов А.Б., 2013). Особую роль в развитии боли играют ионные каналы мембран нервных волокон, способствующих формированию и проведению эктопических разрядов, воспринимаемыхмозгом как боль (Крыжановский Г.Н., 2001). Их структурные повреждения в позвоночнике при его дегенеративных изменениях, отмечаемых при

радикулопатиях, играют роль триггера для формирования хронического болевого синдрома (Yamashita T. et al., 2014).

\section{Пояснично-крестцовая радикулопатия:} клинические особенности

Клиническая картина пояснично-крестцовой радикулопатии состоит из вертебральных симптомов (изменение статики и динамики поясничного отдела позвоночника) и корешковых нарушений (двигательные, чувствительные и вегетативно-трофические нарушения). Пациенты обычно предъявляют характерный набор жалоб в виде таких симптомов, как жжение, прострел, а также каузалгий, вызванных легким прикосновением; симптоматика имеет тенденцию длительно сохраняться с возможностью хронизации процесса. При этом отмечается тенденция к уменьшению или практически прекращению действия анальгезирующих лекарственных средств. Это приводит к нарушениям болевой, температурной и вибрационной чувствительности в соответствующем дерматоме, проявляющимся парестезией, гипер- или гипалгией, аллодинией, гиперпатией. Также определяется снижение или выпадение коленного и ахиллова сухожильных рефлексов, замыкающихся через соответствующий сегмент СМ. Типично наличие симптомов натяжения (Freynhagen R. et al. , 2006). Важной особенностью развития НБС при радикулопатии является нарушение сна, беспокойство, тревога, депрессия. Отмечается значительное снижение качества жизни пациентов (Attal N. et al., 2011; Finnerup N.B. et al., 2016).

При установлении клинического диагноза большую диагностическую ценность представляют выявление двигательных расстройств, выражающихся в парезах определенных мышечных групп, иннервируемых данным корешком. Например, слабость длинного разгибателя большого пальца характерна для сдавления корешка L , слабость икроножной мышцы - корешка S. При парезе разгибателей стопы больные испытывают затруднения при попытке пройтись на пятках, при парезе икроножных мышц или сгибателей стопы - при ходьбе на цыпочках и по ступенькам. Острый двусторонний корешковый синдром (синдром конского хвоста) возникает редко, обычно вследствие массивной срединной (центральной) грыжи нижнепоясничного диска либо стеноза канала. Синдром проявляется быстро нарастающей двусторонней асимметричной болью в ногах, онемением и гипестезией промежности, нижним вялым парапарезом, задержкой мочеиспускания, недержанием кала, развитием перемежающейся хромоты (Yamashita T. et al. , 2014). Пояснично-крестцовая радикулопатия часто сопровождается рядом вегетативных расстройств. Их источником является раздражение многочисленных афферентных сосудодвигательных волокон и рефлекторный спазм сосудов под влиянием болевых ощущений. Они носят симпаталгический характер и проявляются жгучей, колющей, зудящей болью, усиливающейся при перемене погоды, охлаждении ног. К вегетативным расстройствам также относят симптомы трофического характера - цианоз, нарушение потоотделения, сухость и шелушение кожи. Они имеют зональный характер и соответствуют пораженным узлам. Вазомоторные нарушения проявляются в виде зябкости конечности, снижения температуры кожи, спазма, изредка - исчезновения пульса (Johnson E.W., Fletcher F.R., 1981; Woolf C.J. et al., 1998).

\section{Фармакотерапия боли}

\section{при пояснично-крестцовой радикулопатии}

Традиционно для лечения боли в спине применяют нестероидные противовоспалительные препараты (НПВП), которыехорошо купируют ноцицептивную боль, однако неэффективны при нейропатической боли, возникающей при радикулопатии. Неверный выбор тактики лечения у больных с пояснично-крестцовыми радикулопатиями способствует снижению его эффективности и существенному увеличению продолжительности лечения и затрат (Tolle T. et al., 2006). При этом лишь 4,7\% врачей общей практики используют весь перечень рекомендованных лекарственных средств, которые можно было бы применить в качестве препаратов первой линии для купирования НБС (Martinez V. et al., 2014).

Результаты недавних систематических обзоров свидетельствуют, что среди лекарственных средств, применяемых в лечении НБС, наиболее эффективны с клинической точки зрения и безопасности для пациента препараты группы габапентиноидов: прегаба- 
лин и габапентин, что делает их в настоящее время лекарственными средствами первого выбора для устранения боли с нейропатическим компонентом (Finnerup N.B. etal., 2005). Полученные данные об их высокой эффективности и безопасности, доказанных во многих исследованиях, стали поводом для создания протоколов по лечению боли в спине с нейропатическим компонентом, в частности во Франции, Англии и других странах Европейского Союза (Finnerup N.B. et al., 2005; Attal N. et al., 2010; Martinez V. et al., 2010). Так, Французское общество борьбы с болезнями (Société Française d'Etude et de Traitement de la Douleur - SFETD) предложило и распространило основанные на фактических данных рекомендации, ориентированные на врачей общей практики, для повышения эффективности лечения пациентов с нейропатической болью на всех уровнях, включая амбулаторную помощь (Martinez V. et al., 2010), в которых прегабалин указан как препарат первой линии. Препарат с 2004 г. прочно вошел в лечебную практику терапии НБС. На сегодня Европейская комиссия и Управление по контролю за продуктами и лекарственными средствами США одобрили прегабалин в качестве основного средства для лечения периферической нейропатической боли (Moulin D.E. et al., 2007).

Прегабалин - современный антиконвульсант, зарекомендовавший себя как эффективный препарат для лечения любой нейропатической боли, фибромиалгии, тревожных состояний и судорожного синдрома. Прегабалин - (S)-3-(аминометил)-5-метилгексановая кислота) представляет собой габапентиноид нового поколения, синтезированный более четырех десятилетий тому назад как противоэпилептический препарат, - сегодня является средством выбора при радикулопатии с невротическим компонентом (Pérez C. et al., 2013). Это аналог ү-аминомасляной кислоты с высокой селективностью в отношении альфа-2-дельта-субъединицы потенциалзависимого кальциевого канала нейрона. Селективно связываясь с 2-субъединицей кальциевых каналов, он тормозит высвобождение возбуждающих нейромедиаторов и тем самым блокирует передачу болевых импульсов на уровне задних рогов и на более высоких уровнях ЦНС. Его более высокая проницаемость через гематоэнцефалический барьер по сравнению с габапентином делает препарат значительно более эффективным (Freynhagen R. et al., 2005). Способность проявлять свои эффекты лишь в определенных участках ЦНС (в коре головного мозга, обонятельных луковицах, гипоталамусе, амигдале, гиппокампе, мозжечке и задних рогах СМ) определяет его эффективность в подавлении болевых ощущений, а также развития многих психосоматических расстройств (Attal N. et al., 2006).

Поэтому применение прегабалина может препятствовать развитию центральной сенситизации и формированию «болевой памяти", которые поддерживают болевой синдром, тем самым способствуя его регрессу (Field M.J. et al., 2007; Freynhagen R., Baron R., 2009).

Во многих исследованиях показана не только высокая эффективность прегабалина в лечении НБС у пациентов с заболеваниями спины, но также его высокая безопасность по сравнению с другими препаратами. Так, в исследовании, проведенном в Японии в 2016 г., оценивали анальгезирующий эффект прегабалина в зависимости от дозы. Первичной конечной точкой был прямой анальгезирующий эффект - уменьшение выраженности боли в ногах при оценке с использованием визуальной аналоговой шкалы (Visual analogue scale - VAS) (Orita S. et al., 2016). K 6-й неделе лечения у $82,4 \%$ пациентов выраженность боли значительно уменьшилась и в среднем по шкале VAS находилась в пределах $\leqslant 30$ : VAS 0 мм достигнут у $17,5 \%$, высокий уровень ремиссии (10-20 мм) - у 38,6\%, умеренный (30-40 мм) - у 26,3\% пациентов. Отмечены также изменения других физических параметров пациентов. Так, значительно увеличилась дистанция ходьбы, хотя этот показатель не имел статистической достоверности (рис. 2).

Показана более высокая эффективность прегабалина по сравнению с другими препаратами, применяемыми в лечении НБС, обусловленного заболеванием позвоночника. Прегабалин назначали в дозе 150 мг/сут, затем еженедельно дозу повышали до 300 и 600 мг/сут. Спустя 3 нед лечения выявлено достоверное уменьшение выраженности боли в группе прегабалина по сравнению с пациентами, получавшими амитриптилин $(p=0,003)$, габапентин $(p=0,042)$ и плацебо $(p=0,024)$. При этом отмечено значительное снижение доз вводимых анальгетиков на фоне приема прегабалина (Baron R. et al., 2010). Уменьшение выраженности боли в более чем 2 раза отмечали у $63 \%$ пациентов, получавших монотерапию прегабалином, и у $56 \%$, применявших прегабалин как дополнение к традиционной терапии, включавшей НПВП, транквилизаторы, амитриптилин и фентанил. У пациентов отмечено улучшение качества жизни, включая самообслуживание и повседневную активность, снижение выраженности проявлений тревожно-депрессивных расстройств, ассоциированных с болевым синдромом (Gore M. et al., 2007) (рис. 3 и 4).

Эффективная доза препаратапри НБС, вызванном патологией позвоночника, зависит от ряда факторов. Но в рандомизированных клинических исследованиях установлена эффективная и безопасная терапевтическая доза 160-600 мг/сут (Taguchi T. et al., 2015). При этом в исследованиях, проведенных в условиях реальной клинической практики, продемонстрирована высокая анальгезирующая активность прегабалина и в более низких суточных дозах (Gore M. et al., 2007). Так, при пояснично-крестцовой и шейной радикулопатии эффективная доза составляла 190 мг. Как правило, стартовая суточная доза составляет 150 мг (по 75 мг 2 раза в сутки, утром и вечером). Через 3-7 дней от старта осуществляется переход на оптимальную суточную дозу 300 мг (по 150 мг 2 раза в сутки); при необходимости через 10-14 дней возможно повышение дозы прегабалина до максимальной - 600 мг/сут (по 300 мг 2 раза в сутки) (Eccleston C. et al., 2015).

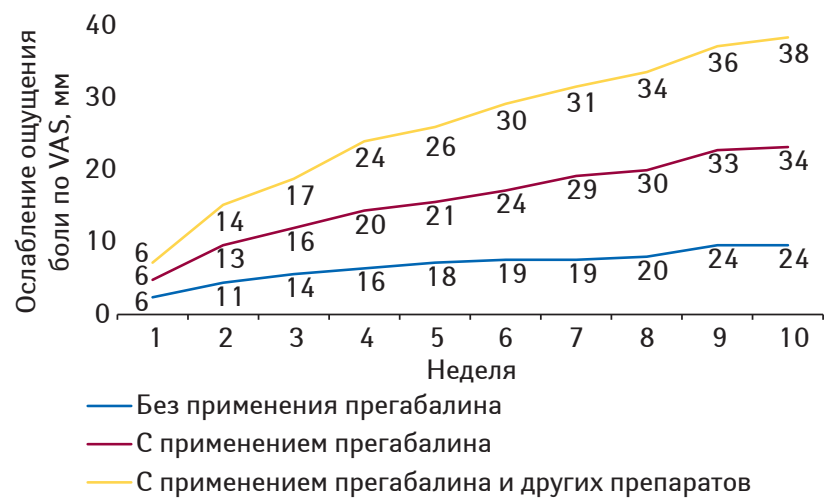

Рис. 2. Изменение ощущения боли

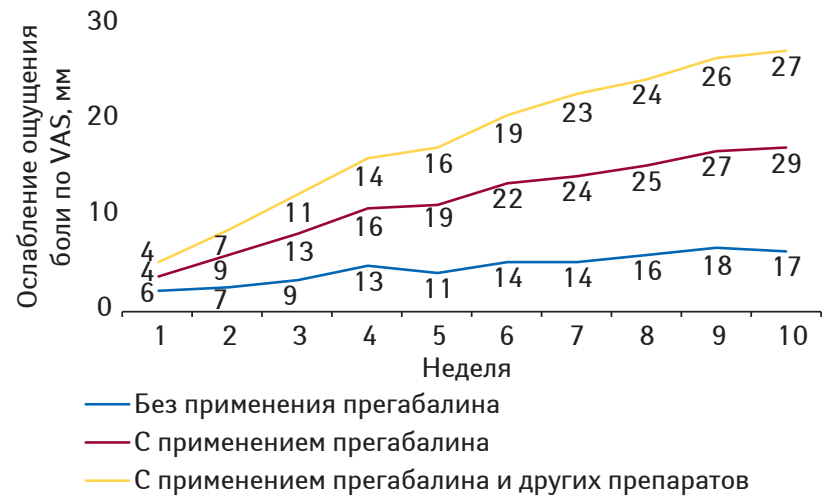

Рис. 3. Улучшение качества жизни

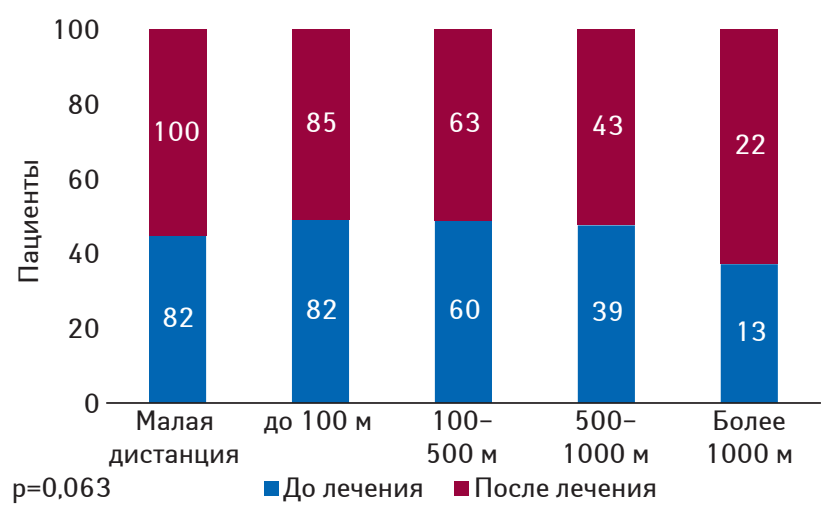

Рис. 4. Увеличение дистанции ходьбы 


\section{Заключение}

Имеющиеся в настоящее время доказательства высокой эффективности прегабалинадля лечения НБС как в монотерапии, так и в комбинации с другими лекарственными средствами, позволяют применять его в качестве препарата выбора или средства первой линии, в том числе при радикулопатии. Комбинация прегабалина с другими препаратами, в частности НПВП, способствует более эффективному купированию болевого синдрома, уменьшает выраженность тревожно-депрессивных расстройств, а также способствует улучшению качества жизни пациентов с радикулопатией.

Естественным является вопрос наличия препарата в аптечной сети, приемлемая для украинского потребителя цена и высокое качество. Одним из представителей прегабалина на рынке Украины является препарат швейцарского производства Неогабин, соответствующий всем международным стандартам качества, предъявляемым к лекарственным средствам.

\section{Список использованой литературы}

Воробьева 0. (2014) Консервативное лечение пояснично-крестцовой радикулярной боли. Врач, 9: 8-11.

Данилов А.Б., Данилов Ал.Б. (2013) Биопсихосоциокультурная модель и хроническая боль. Соврем. тер. псих. неврол., 1: 30-36.

Крыжановский Г.Н. (2001) Центральные патофизиологические механизмы патологической боли. Науч.-практ. конф. с междунар. участием «Клинические и теоретические аспекты боли». Москва, 14 с.

Andre V., Rigoulot M.A., Koning E. (2003) Long-term pregabalin treatment protects basal cortices and delays the occurrence of spontaneous seizures in the lithiumpilocarpine model in the rat. Epilepsia, 44: 893-903.

Attal N., Cruccu G., Baron R. et al. (2010) European Federation of Neurological Societies: EFNS guidelines on the pharmacological treatment of neuropathic pain: 2010 revision. Eur. J. Neurol., 17: e1113-e1188.

Attal N., Cruccu G., Haanpaa M. et al. (2006) EFNS guidelines on pharmacological treatment of neuropathic pain. Eur. J. Neurol., 13: 1153-1169.

Attal N., Fermanian C., Fermanian J. et al. (2008) Neuropathic pain: are there distinct subtypes depending on the aetiology or anatomical lesion? Pain, 138(2): 343-353.

Attal N., Lanteri-Minet M., Laurent B. et al. (2011) The specific disease burden of neuropathic pain: results of a French nationwide survey. Pain, 152: 2836-2843.

Baron R., Freynhagen R., Tölle T.R. et al. (2010) The efficacy and safety of pregabalin in the treatment of neuropathic pain associated with chronic lumbosacral radiculopathy. Pain, 150(3): 420-427 (doi: 10.1016/j.pain.2010.04.013).

Berger A., Dukes E.M., Oster G. (2004) Clinical characteristics and economic costs of patients with painful neuropathic disorders. J. Pain, 5: 143-149.

Centre for Clinical Practice at NICE (UK) (2010) Neuropathic pain: the pharmacological management of neuropathic pain in adults in non-specialist settings. London National Institute for Health and Clinical Excellence (UK).

Colloca L., Ludman T., Bouhassira D. et al. (2017) Neuropathic pain. Nat. Rev. Dis. Primers, 3: 17002.

Eccleston C., Hearn L., Williams A.C. (2015) Psychological therapies for the management of chronic neuropathic pain in adults. Cochrane Database Syst. Rev., 10: CD011259.

Field M.J., Li Z.,Schwarz J.B. (2007) $\mathrm{Ca}^{2+}$ channel alpha2-delta ligands for the treatment of neuropathic pain. J. Med Chem., 50(11): 2569-2575.

Finnerup N.B., Haroutounian S., Kamerman P. et al. (2016) Neuropathic pain: an updated grading system for research and clinical practice. Pain, 157(8): 1599-1606.

Finnerup N.B., Otto M., McQuay H.J. et al. (2005) Algorithm for neuropathic pain treatment - an evidence based proposal Pain, 118(3): 289-305.

Freynhagen R., Baron R. (2009) The evaluation of neuropathic components in low back pain Curr. Pain Headache Rep., 13(3): 185-190.

Freynhagen R., Baron R., Tölle T. et al. (2006) Screening of neuropathic pain components in patients with chronic back pain associated with nerve root compression: a prospective observational pilot study (MIPORT) Curr. Med. Res. Opin., 22: 529-537.

Freynhagen R., Strojek K., Griesing T. et al. (2005) Efficacy of pregabalin in neuropathic pain evaluated in a 12-week, randomised, double-blind, multicentre, placebocontrolled trial of fable- and fixed-dose regimens. Pain, 115(3): 254-263.

Gore M., Dukes E., Rowbotham D.J. et al. (2007) Clinical characteristics and pain management among patients with painful peripheral neuropathic disorders in general practice settings. Eur. J. Pain, 11(6): 652-664.

Hurley R.W., Chatterjea D., Rose F.M. et al. (2002) Gabapentin and pregabalin can interact synergistically with naproxen to produce antihyperalgesia. Anesthesiology, 97: 1263-1273.

Johnson E.W., Fletcher F.R. (1981) Lumbosacral radiculopathy: review of 100 consecutive cases. Arch. Phys. Med. Rehabil., 62(7): 321-323.

Knight T., Schaefer C., Chandran A. et al. (2013) Health-resource use and costs associated with fibromyalgia in France, Germany, and the United States. Clinicoecon. Outcomes Res., 5: 171-180.
Martinez V., Attal N., Bouhassira D. et al. (2010) Chronic neuropathic pain: diagnosis, evaluation and treatment in outpatient services. Guidelines for clinical practice of the French Society for the Study and Treatment of Pain. Douleur analg., 23: 51-66.

Martinez V., Attal N., Vanzo B. et al. (2014) Adherence of French GPs to chronic neuropathic pain clinical guidelines: results of a cross-sectional, randomized, «e» case-vignette survey. PLoS One, 9(4): e93855.

Moulin D.E., Clark A.J., Gilron I. et al. (2007) Pharmacological management of chronic neuropathic pain-consensus statement and guidelines from the Canadian Pain Society. Pain Res. Manag., 12(1): 13-21.

Orita S., Yamashita M., Eguchi Y. et al. (2016) Pregabalin for Refractory Radicular Leg Pain due to Lumbar Spinal Stenosis: A Preliminary Prospective Study. Pain Res. Manag. (https://www.hindawi.com/journals/prm/2016/5079675/).

Pérez C., Navarro A., Saldaña M.T. et al. (2013) Clinical and resource utilization patterns in patients with refractory neuropathic pain prescribed pregabalin for the first time in routine medical practice in primary care settings in Spain. Pain Med., 14(12): 1954-1963.

Radat F., Margot-Duclot A., Attal N. (2013) Psychiatric co-morbidities in patients with chronic peripheral neuropathic pain: a multicentre cohort study. Eur. J. Pain, 17(10): 1547-1557.

Taguchi T., Igarashi A., Watt S. et al. (2015) Effectiveness of pregabalin for the treatment of chronic low back pain with accompanying lower limb pain (neuropathic component): a non-interventional study in Japan. J. Pain Res., 8: 487-497.

Tesfaye S., Boulton A.J., Dickenson A.H. et al. (2013) Mechanisms and management of diabetic painful distal symmetrical polyneuropathy. Diabetes Care, 36: $2456-2465$

Tolle T., Dukes E., Sadosky A. et al. (2006) Patient burden of trigeminal neuralgia: results from a cross-sectional survey of health state impairment and treatment patterns in six European countries. Pain Pract., 6(3): 153-160.

Toth C. (2014) Pregabalin: latest safety evidence and clinical implications for the management of neuropathic pain. Ther. Adv. Drug Saf., 5(1): 38-56.

Woolf C.J., Bennett G.J., Doherty M. et al. (1998) Towards a mechanism-based classification of pain? Pain, 77(3): 227-229.

Yamashita T., Takahashi K., Yonenobu K. et al. (2014) Prevalence of neuropathic pain in cases with chronic pain related to spinal disorders. J. Orthop. Scien., 19(1): 15-21.

Yarnitsky D. (2015) Role of endogenous pain modulation in chronic pain mechanisms and treatment. Pain, 156: S24-S31.

\section{Медикаментозна стратегія лікування нейропатичного больового синдрому при радикулопатії}

\section{O.I. Осадчий}

Резюме. Уоглядіпродемонстровано актуальність проблемипоперековокрижової радикулопатії. Представлені епідеміологічні дані, причини, механізми розвитку, клінічна картина і методи фармакотерапії нейропатичного болюпри радикулопатії. Наведенірекомендації міжнародних організацій з лікування болю. Описана ефективність ібезпека габапентиноїдів, в тому числі прегабаліну як препарату останньої генерації, рекомендованого для лікування нейропатичного болю. Його клінічна ефективність при лікуванні нейропатичного больового синдрому вивчена у ряді клінічних рандомізованих досліджень, які продемонстрували його анальгезуючудію, а такожздатність сприяти регресу супутніх психосоматичних розладів та інсомнії у пацієнтів із попереково-крижовою нейропатією.

Ключові слова: хронічний біль, біль в спині, нейропатичний біль, ноцицептивний біль, габапентиноїди, прегабалін, радикулопатія.

\section{Drug strategy of treatment of neuropathic pain syndrome in radiculopathy}

\section{A.I. Osadchy}

Summary. Actuality of problem of radiculopathy is shown in the review. Epidemiology data, reasons, mechanisms of development, clinical presentation and methods of drug treatment of neuropathic pain in radiculopathy are presented. Recommendations of the international organizations for the treatment of the pain are given. Efficiency and safety of gebapenthinoides are described, including pregabalin, as the drug of the last generation, recommended for treatment of neuropathic pain. Its clinical efficiency in treatment of neuropathic pain syndrome was studied in a number of clinical randomized researches, showing its analgetic action and also ability to cause regress of concomitant psychosomatic disorders and insomnia in patients with lumbosacral neuropathy.

Key words: chronic pain, back pain, neuropathic pain, nociceptive pain, gebapenthinoides, pregabalin, radiculopathy.

UA-NEOG-PUB-102018-011 